\title{
DECRESCIMENTO E BEM VIVER: PARADIGMAS PARA O MUNDO PÓS-PANDEMIA?
}

\author{
Nathan Pereira Dourado ${ }^{1}$ \\ Marlene Grade ${ }^{2}$
}

\begin{abstract}
Resumo: A pandemia provocada pelo novo coronavírus tem explicitado e agravado a crise do capitalismo, deixando-o diante de seus próprios limites de autorreprodução e, portanto, à beira do colapso. Partimos do entendimento de que a pandemia não surge do acaso, e sim como resultado do desequilíbrio ecológico, causado pela produção destrutiva do capitalismo globalizado. Neste trabalho discutimos as causas e os efeitos da pandemia, a sua relação com a crise ecológica, seus desdobramentos e possíveis respostas, com o intuito de contribuir com o debate recém-inaugurado: o mundo pós-pandemia. Nossa análise é, assumidamente, anticapitalista, dialética, crítica e esperançosa. O objetivo final deste trabalho é estabelecer um nexo entre os paradigmas do decrescimento e do Bem Viver, como possíveis alternativas para o mundo pós-pandemia.
\end{abstract}

Palavras-chave: Crise Civilizatória. Crise Capitalista. Alternativas ao Capitalismo. COVID-19.

Abstract: The pandemic caused by the new coronavirus has avowed and worsened the crisis of capitalism, which faces its limits of self-reproduction and, therefore, it is on the brink of collapse. We assume that a pandemic does not appear by accident, but because of the ecological imbalance, resulting from the destructive production model of global capitalism. In this paper we discuss the causes and effects of the pandemic, its relationship with ecological crisis, its consequences, and possible responses, to contribute to a recently opened debate: the post-pandemic world. Our analysis is supposedly anti-capitalist, dialectical, critical, and trustful. The final objective of this work is to establish a link between the Degrowth and Good Living paradigms, as possible alternatives for the postpandemic world.

Keywords: Civilization Crisis. Capitalist Crisis. Alternatives to Capitalism. COVID19.

\footnotetext{
1 Universidade Federal da Bahia. E-mail: npdourado@hotmail.com.

Link para o Lattes: http://lattes.cnpq.br/1356185973340346

2 Universidade Federal de Santa Catarina. E-mail: marlene.grade@ufsc.br.

Link para o Lattes: http://lattes.cnpq.br/0499939362814355
} 


\section{Introdução}

A pandemia provocada pelo novo coronavírus tem explicitado e agravado a profunda crise estrutural do capitalismo, deixando-o diante de seus próprios limites de reprodução e, portanto, à beira de um colapso. A pandemia não é fruto do acaso, pelo contrário "ela é uma consequência, reiteradamente prevista, de um sistema socioeconômico crescentemente disfuncional $e$ destrutivo" (MARQUES, 2020, s/p). Trata-se, portanto, de "uma manifestação entre muitas do modelo de sociedade que começou a se impor globalmente a partir do século XVII e que está hoje a chegar à sua etapa final' (SANTOS, 2020, p. 23).

Como se sabe, os vírus são organismos incapazes de se autorreproduzir, pois necessitam de outras vidas (hospedeiros) para isso; também o capitalismo, como tal, não se reproduz/sobrevive sem explorar outras vidas (natureza e trabalho). Visto assim, consideramos que o capitalismo e o coronavírus têm uma característica em comum: o parasitismo. Além disso, ainda por analogia, testemunhamos o novo coronavírus se expandir globalmente tal qual o capitalismo, sem barreiras capazes de detê-lo.

O caráter destrutivo do processo de acumulação capitalista em escala global apresenta sinais cada vez mais evidentes de esgotamento. Por essas razões, o sistema capitalista, nos atuais moldes, ainda que consiga sobreviver à pandemia, carrega como maior desafio o de se manter sem destruir as condições fundamentais à continuidade da vida humana digna no planeta (SANTOS, 2020; FOSTER, 2020; MARQUES, 2018; LOWY, 2013; MÉSZÁROS, 2011).

Para além de um modo de produção, o capitalismo representa uma forma societária e um modelo de desenvolvimento, baseado em um padrão de racionalidade e um sistema de valores, que se expressa no tipo de relação dos homens e mulheres entre si e com a natureza. Este entendimento leva a crer que não se trate somente de uma crise do sistema econômico, mas de uma crise civilizatória, uma crise de um modo de vida e de um padrão de racionalidade. Em última análise, o que está em jogo é a busca por um novo paradigma civilizatório (LOWY, 2013; LEFF, 2006; PORTO-GONÇALVES, 2004).

Intelectuais renomados afirmam estarmos diante da maior crise da história do capitalismo, e assinalam que o mundo não será o mesmo depois que a pandemia for controlada (HARVEY, 2020; SANTOS, 2020; DAVIS, 2020). O filósofo político Slavoj Zizek (2020), recentemente publicou um artigo no qual compara, metaforicamente, a pandemia do coronavírus à "técnica de cinco pontos para explodir o coração" ${ }^{3}$ - golpe mais fatal das artes marciais -, "destinada ao sistema capitalista global". "É um sinal de que não podemos continuar no caminho em que temos estado até agora, de que é necessária uma mudança radical' (ZIZEK, 2020, p. 44).

\footnotetext{
${ }^{3}$ Cena final da obra cinematográfica "Kill Bill: volume 2", do diretor Quentin Tarantino (2004).
}

revista brasileira educação ambiental 
É provável que a atual crise da pandemia de coronavírus culmine com o fim de um ciclo, abrindo espaço para a gestação de um novo modelo de sociedade assentado em outros paradigmas, valores e visões de mundo (CASTELLS, 2020; SANTOS, 2020; ACOSTA, 2020; KRENAK, 2020), no dizer de Foster: "a sociedade terá que ser reconstituída sobre uma base radicalmente nova" (2020, s/p). Com efeito, "esta situação torna-se propícia a que se pense em alternativas ao modo de viver, de produzir, de consumir e de conviver nestes primeiros anos do século XXl" (SANTOS, 2020, p.29), processo que Santos $(2020$, p.32) denomina de "viragem epistemológica, cultural e ideológica".

Este debate nos remete às propostas do decrescimento e do Bem Viver. Conceitos originários de países e contextos culturais distintos, mas que têm em comum 0 fato de se apresentarem como matrizes de alternativas anticapitalistas e pós-desenvolvimentistas, ancoradas por uma profunda mudança de paradigma. Estas propostas são plurais e não fornecem modelos prontos. Em muitos casos, já estão colocadas, em movimento, no cotidiano das re-existências e lutas anticapitalistas de comunidades espalhadas ao redor do mundo.

Nas seções seguintes, aprofundamos o debate sobre a crise do capitalismo, com ênfase na dimensão ecológica, articulando com 0 atual momento da pandemia. Abordamos também as causas, os efeitos e os possíveis desdobramentos da crise pandêmica.

Nas seções finais, apresentamos e articulamos os conceitos de decrescimento e Bem Viver, procurando compreender em que medida a convergência destes conceitos fornecem saídas ao atual impasse civilizatório.

\section{A crise capitalista em tempos-espaços de pandemia}

Avaliamos que a atual crise global do capitalismo não se trata de uma crise conjuntural. Cabe destacar que o sistema capitalista enfrenta, desde a década de 1970, uma profunda crise estrutural ${ }^{4}$ e sistêmica, oriunda da sua própria lógica de funcionamento, baseada na dinâmica incessante de acumulação do capital em expansão, na exploração do trabalho e na devastação da natureza (HARVEY, 2016; MÉSZAROS, 2011; WALLERSTEIN, 2010). Citando Marx: "a produção capitalista produz a sua própria negação" (MARX, 1984, p.381).

Expansionista, destrutivo e, no limite, incontrolável, o capital assume cada vez mais a forma de uma crise endêmica, como um depressed continuum, como uma crise cumulativa, crônica e permanente, com a perspectiva de uma crise estrutural cada vez mais profunda (MESZÁROS, 2011, p. 18).

${ }^{4}$ Difere, portanto, das crises conjunturais periódicas, pois aponta para o debilitamento de todo um regime político (MÉSZÁROS, 2011). 
Nesse sentido, à medida que a crise deixa de parecer transitória, a legitimidade do sistema capitalista passa a ser fortemente questionada, devido ao fato de este modelo econômico se mover mais pelos interesses da elite, vinculados ao lucro, do que pelas reais necessidades da coletividade e, portanto, por não apresentar resultados positivos para a maioria da população mundial.

A tese fundamental é simples: o sistema capitalista necessita urgentemente ser revisto, pois é incompatível com a manutenção dos equilíbrios ecológicos e sociais. Já fomos alertados sobre o fato de estarmos diante de uma crise terminal (WALLERSTEIN, 2010) e de um caos sistêmico (ARRIGHI, 2011). Tais formulações revelam a perecibilidade do capitalismo e a necessidade de sua superação histórica. Neste sentido, Besson-Girard (2012) traz a noção de "mundo em transição", ao enfatizar o caráter dinâmico do processo histórico, sugerindo, porém, dentro deste processo, "a existência de níveis de aceleração ou sobreaquecimento capazes de provocar rupturas totalmente inéditas" (BESSON-GIRARD, 2012, p.376). Consideramos a atual crise desencadeada pela pandemia de coronavírus como um evento causador de sobreaquecimento, pois torna mais visíveis e cruéis as desigualdades geradas pelo capitalismo.

A política neoliberal, adotada pelos Estados nos últimos quarenta anos, como forma de lidar com a crise estrutural, no sentido de garantir a sobrevivência do capitalismo, através da manutenção das taxas de lucro, acima de tudo e de todos, gerou um aprofundamento das desigualdades, violações dos direitos sociais e destruição da natureza (HARVEY, 2020; SANTOS, 2020; NETO; CASTRO, 2020). Como resultado, pode-se afirmar que o capitalismo, em sua versão neoliberal, criou um ambiente extremamente favorável à disseminação do vírus (SANTOS, 2020; HARVEY, 2020). "A pandemia é a expressão máxima do acúmulo de contradições do modelo neoliberal" (NETO; CASTRO, 2020, p.3).

No lugar de somente uma crise econômica conjuntural, vivemos uma convergência de crises: ambiental, social, política, energética, climática, alimentar, ética e, mais recentemente, soma-se a este quadro a crise de saúde pública. Podemos dizer que todas estas crises, que ameaçam a humanidade, estão interconectadas e são resultantes de um mesmo fenômeno: "um sistema que transforma tudo - a terra, a água, o ar que respiramos, os seres humanos - em mercadoria, e que não conhece outro critério que não seja a expansão dos negócios e a acumulação de lucros" (LOWY, 2013, p. 80).

Diante de um cenário de saturação e incapacidade do capitalismo em fornecer respostas à permanente e aguda crise sobre a qual dialogamos até aqui, fica a seguinte pergunta: o capitalismo poderá sobreviver? De acordo com Mandel (1981), para que um sistema político-econômico desapareça, não é somente necessário que exista uma força social de contestação. Também não basta que ele tenha dado provas da sua irracionalidade; é preciso que ele 
engendre obstáculos cada vez mais intransponíveis ao seu próprio desenvolvimento.

\section{A crise ecológica e sua relação direta com a pandemia}

Situamos a crise ecológica como efeito do processo de acumulação capitalista e da sua necessidade de expansão ilimitada, anteriormente abordada. Tal crise apresenta sinais alarmantes, referendados por diversas pesquisas cientificas, a saber: crescimento exponencial das poluições do ar, da água potável e do meio ambiente em geral; destruição da camada de ozônio; erosão da biodiversidade e desaparecimento de espécies; destruição, cada vez mais acelerada, das florestas tropicais; esgotamento dos solos, desertificação; contaminação por resíduos tóxicos; ameaça de novos acidentes nucleares; contaminação alimentar pelo uso de agrotóxicos; manipulações genéticas e surgimento de novas doenças etc. (MARQUES, 2018; LOWY, 2013; LÉNA, 2012).

Todos os faróis estão no vermelho: é evidente que a corrida louca atrás do lucro, a lógica produtivista e mercantil da civilização capitalista e industrial nos leva a um desastre ecológico de proporções incalculáveis (LOWY, 2013, p.80).

Segundo Foster (2020, s/p):

Seria um grave erro não compreender que a crise ecológica planetária e a crise da economia capitalista global são elementos dialeticamente interconectados de uma crise estrutural do capital que define nossa época.

A pandemia de coronavírus surge quando as mudanças climáticas e os processos de degradação ambiental estão em aceleração. Não se trata de ceder ao catastrofismo, mas de simplesmente constatar que a dinâmica capitalista ameaça destruir a vida humana no planeta (SANTOS, 2020; ACOSTA, 2020; LOWY, 2013).

Como se sabe, a difusão de vírus é resultante de mutações, diretamente ligadas às condições ambientais, que são determinadas, dentre outros fatores, pela intervenção humana, a exemplo da devastação dos ecossistemas naturais causada pelo agronegócio. Há evidências científicas que associam a origem da pandemia ao sistema agroalimentar industrializado e intensivo (agronegócio) modelo hegemônico de produção agropecuária amplamente difundido desde os anos 1970 - que se expandiu no mundo através da ofensiva neoliberal das chamadas "corporações-monstro" (MÉSZÁROS, 2007). Este modelo produtivo é altamente impactante para a saúde humana, os ecossistemas e o clima mundial (ALTIERI; NICHOLLS, 2020; GLIESMANN, 2020). De acordo com Hendrickson (2020, n.p): "levou apenas 6 semanas para a pandemia de 
COVID-19 expor brutalmente as falhas do nosso sistema alimentar moderno falhas documentadas pelos cientistas por décadas".

O epidemiologista Rob Wallace (2016) explica que a destruição dos ecossistemas naturais, combinada com a homogeneização e simplificação genética, associadas à agropecuária intensiva, criam condições favoráveis à disseminação maciça de vírus e doenças. É bem provavél que novas pandemias ocorram, caso não sejamos capazes de promover as mudanças necessárias no sistema agroalimentar mundial.

Em resumo, o aquecimento global, o desmatamento, a destruição dos habitats selvagens, a domesticação e a criação de aves e mamíferos em escala industrial destroem o equilíbrio evolutivo entre as espécies, facilitando as condições para saltos desses vírus de uma espécie a outra, inclusive a nossa. (MARQUES, 2020, s/p).

A pandemia de coronavírus traz à tona o conceito de saúde única, o qual reconhece que a saúdes humana, animal e do ambiente estão intimamente ligadas (ALTIERI; NICHOLLS, 2020), sendo o regime capitalista uma enfermidade que ameaça essa saúde única. Tal entendimento implica, necessariamente, em "que não se pode defender a vida humana na terra sem defender, ao mesmo tempo, no mesmo movimento, as condições da própria vida nesta terra" (QUIJANO, 2013, p.54).

\section{A dialética dos efeitos decorrentes da pandemia da COVID-19 no mundo}

Desde o dia 11 de março deste ano, quando a Organização Mundial da Saúde (OMS) declarou estado de pandemia da COVID-19, e boa parte dos governos passou a adotar medidas de restrição e isolamento social para conter a proliferação do vírus, passamos a observar uma redução drástica nos ritmos de produção, consumo e fluxos de circulação de pessoas e mercadorias. O mundo mudou em apenas três meses, em garantia da vida. A profunda recessão da economia global já é algo inevitável. De acordo com as previsões, o PIB global cairá cerca de 6\% em 2020 (IEA, 2020).

De acordo com Harvey (2020, p.20), as economias capitalistas contemporâneas são $70-80 \%$ impulsionadas pelo consumismo, em especial as formas do "consumismo experiencial" desde o início da pandemia: "grande parte do modelo de vanguarda do consumismo capitalista é inoperante nas condições atuais [...] a forma espiral

\footnotetext{
5 Tradução nossa.

${ }^{6}$ Como por exemplo: companhias aéreas, hotéis, restaurantes, parques temáticos e eventos.
} 
de acumulação interminável de capital está implodindo". Para se ter uma ideia, o número de voos diários caiu na faixa de $70 \%$ entre os dias 16 e 30 de março (Figura 1).

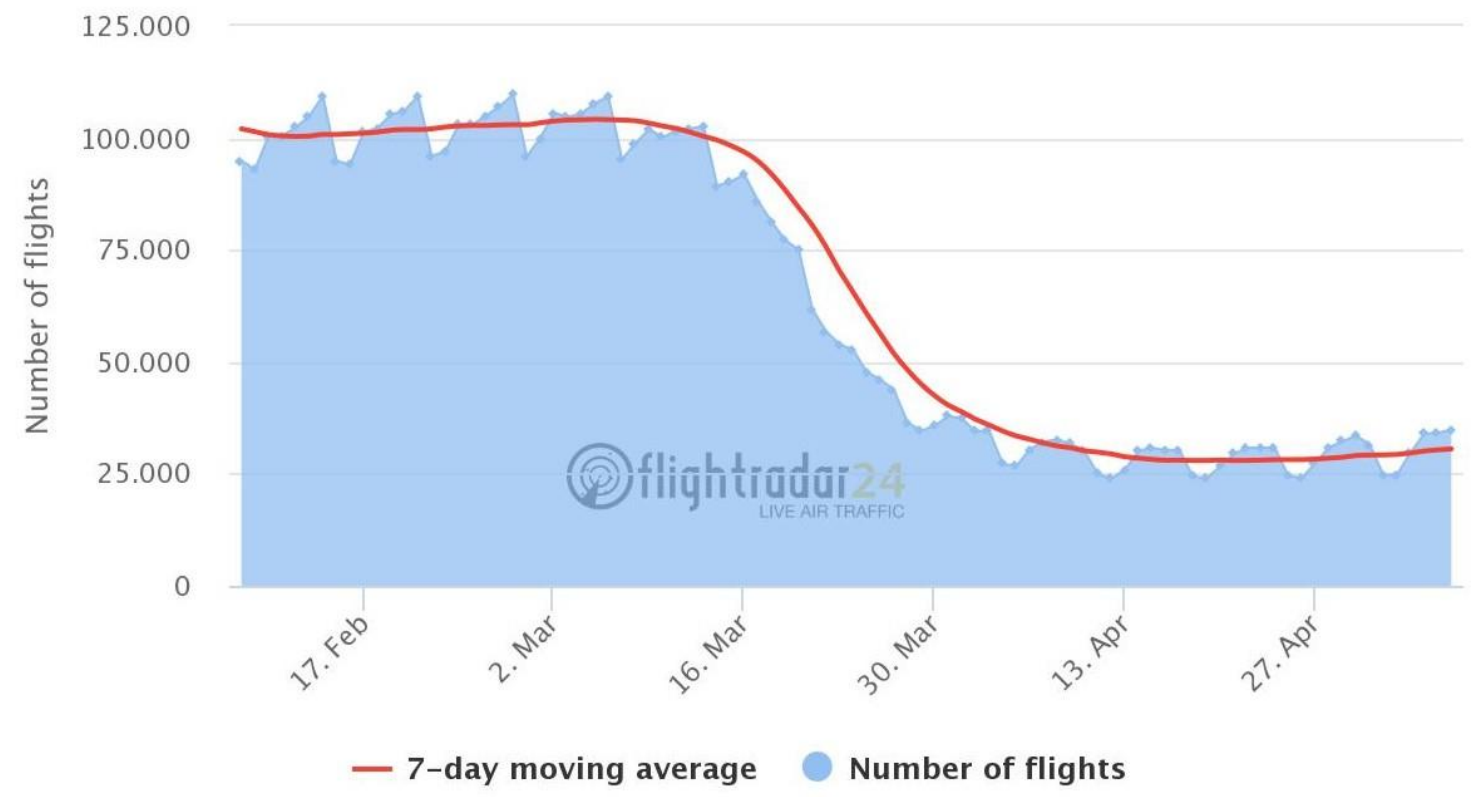

Figura 1: Número de voos rastreados por dia (UTC time).

Fonte: Flighttradar24.

Por outro lado, por meio das restrições advindas da pandemia, aprendemos que boa parte dos milhares de voos cancelados são, na verdade, dispensáveis para a humanidade, e poderiam, de forma organizada, ser reduzidos sem grandes transtornos, se o intuito fosse o de reduzir a nossa pegada ecológica ${ }^{7}$, visto que se trata do meio de transporte mais poluente do mundo.

A pandemia está desarticulando as cadeias produtivas globais e potencializando as cadeias curtas. As sociabilidades estão mudando com a quarentena: temos visto o surgimento de novas formas de solidariedade, maneiras de se relacionar, hábitos de consumo, relações de trabalho. Em oposição, há um expressivo aumento do desemprego e da desigualdade, inerentes ao capitalismo, expondo uma realidade na qual os mais pobres são os que mais sofrem com a pandemia, sem garantia de renda, segurança alimentar, segurança sanitária e direito à saúde (HARVEY, 2020; DAVIS, 2020; SANTOS, 2020).

7 Metodologia criada na década de 1990, que nos ajuda a perceber o impacto exercido por nosso estilo de vida sobre o planeta, e por meio da qual também podemos enxergar os problemas de desigualdade e injustiça. 
O vírus é democrático, dizem por aí, e é verdade; o vírus não escolhe classe social, raça, cor, idade nem endereço para contaminar, porém impacta de maneira diferente, de acordo com o grau de vulnerabilidade dos grupos sociais. Em boa parte dos países, nem todos têm as mesmas oportunidades acessar hospitais, remédios e isolamento social; em suma, alguns podem ficar confortavelmente isolados em casa (trabalhando ou não), enquanto milhões de trabalhadores mais pobres têm que fazer a difícil escolha entre renda ou proteção. De acordo com os dados: "Atualmente, $45 \%$ da força de trabalho não tem esse direito e é praticamente obrigada a transmitir a infecção ou ficar com o prato vazio" (DAVIS, 2020, p. 9). Por outras palavras, "estamos enfrentando uma injustiça pandêmica" (SATO; SANTOS; SÁNCHEZ, 2020, p. 11).

Além disso, quarenta anos de hegemonia neoliberalista deixaram o sistema público totalmente exposto e mal preparado para enfrentar uma crise de saúde pública deste tipo (HARVEY, 2020). Tal despreparo tem razões evidentes:

A indústria farmacêutica tem pouco ou nenhum interesse na pesquisa sem fins lucrativos sobre doenças infecciosas. A indústria farmacêutica raramente investe em prevenção. Tem pouco interesse em investir na preparação para uma crise de saúde pública. Quanto mais doentes nós estamos, mais eles ganham. A prevenção não contribui para uma valorização dos acionistas (HARVEY, 2020, p.18).

Os valores neoliberais, cada vez mais fortes e presentes nos governos de direita e, também, entre as pessoas: individualismo, competição, privatização, austeridade etc., estão postos em xeque, e os valores de cooperação, solidariedade, ajuda mútua, interdependência e reciprocidade estão ganhando espaço. "Isso é algo que o vírus, sem possuir qualquer racionalidade, está nos ensinando a partir de nossas vulnerabilidades" (GIATTI, 2020, p.36). David Harvey corrobora com este raciocínio ao afirmar:

As forças de trabalho na maioria das partes do mundo há muito que foram socializadas para se comportarem como bons sujeitos neoliberais (o que significa culpar a si mesmos ou a Deus se algo de ruim acontecer, mas nunca ousar sugerir que o capitalismo pode ser o problema). Mas mesmo os bons sujeitos neoliberais podem ver que há algo errado com a forma como esta pandemia está sendo enfrentada (HARVEY, 2020, p. 22).

Nesse sentido, o papel do Estado está sendo fortemente questionado 
neste momento. O conselho editorial do jornal britânico The Financial Times ${ }^{8}$, no dia 3 de abril de 2020, surpreendeu a todos ao afirmar que:

Assim como a luta para conter a pandemia expôs o despreparo dos sistemas de saúde, a fragilidade da economia em muitos países também foi exposta [...] Reformas radicais, que revertam a direção tomada nas últimas quatro décadas, deverão ser discutidas. Os governos devem aceitar um papel mais ativo na economia. Eles precisam começar a ver os serviços públicos como investimentos, e não como gastos, e também buscar soluções para tornar os mercados de trabalho menos precários. A redistribuição (da riqueza) voltará ao centro dos debates e os privilégios dos mais ricos deverão ser questionados. As políticas até recentemente consideradas excêntricas, como renda básica universal e a taxação de grandes fortunas, também precisam ser consideradas (THE EDITORIAL BOARD, 2020, s/p, tradução nossa).

Segundo Castells (2020), "fica evidente, agora, para além do sistema de saúde, a necessária prioridade do setor público na organização da economia e da sociedade". Porto Gonçalves (2020), ao ponderar sobre esse fato, alerta que não devemos nos iludir com os neoliberais convertidos em neokeynesianos de uma hora para outra. Segundo o autor:

O keynesianismo, devíamos saber, é um conjunto de políticas de um capitalismo moribundo, em decadência, procurando equilibrar-se lançando mão de artifícios que vão além do mercado, para salvá-lo. Não nos surpreendamos quando em seus momentos de crise aguda a mão visível do Estado se faça presente para resolver o que a mão invisível do mercado não consegue (PORTO-GONÇALVES, 2020, p.3).

No campo ambiental, estudos revelam que já está havendo a diminuição da degradação ecológica e redução nas emissões de $\mathrm{CO}_{2}$ a níveis tão impressionantes que conferências e tratados mundiais sobre meio ambiente não foram capazes de promover ao longo das últimas três décadas. O relatório A Global Energy Review 2020 - The impacts of the COVID-19 crisis on global energy demand and $\mathrm{CO}_{2}$ emission, publicado em abril pela Agência Internacional de Energia (IEA), apresenta a análise dos dados diários coletados até meados de abril, os quais mostram que os países em bloqueio total apresentaram um declínio médio de $25 \%$ na demanda de energia por semana, e os países em bloqueio parcial apresentam um declínio médio de $18 \%$. A

${ }^{8}$ Considerada a bíblia do neoliberalismo. 
estimativa é de que as emissões globais de $\mathrm{CO}_{2}$ sejam $8 \%$ mais baixas que em 2019 (Figura 2).



Figura 2: Taxas de variação (\%) na demanda global de energia primária, 1900 - 2020.

Fonte: IEA (2020, p.11).

Para se ter uma ideia, tomando como base os dados fornecidos pelo relatório do IEA (2020), a demanda por petróleo teve uma queda de $5 \%$ no primeiro trimestre. No final de março, a atividade global de transporte rodoviário estava quase $50 \%$ abaixo da média de 2019 e a aviação $60 \%$ abaixo. O relatório aponta ainda que, enquanto a demanda por energia pode cair $6 \%$ até o final de $2020^{9}$, o crescimento na demanda por energias renováveis registrou aumento de $1,5 \%$ já no primeiro trimestre de 2020 (Figura 3).

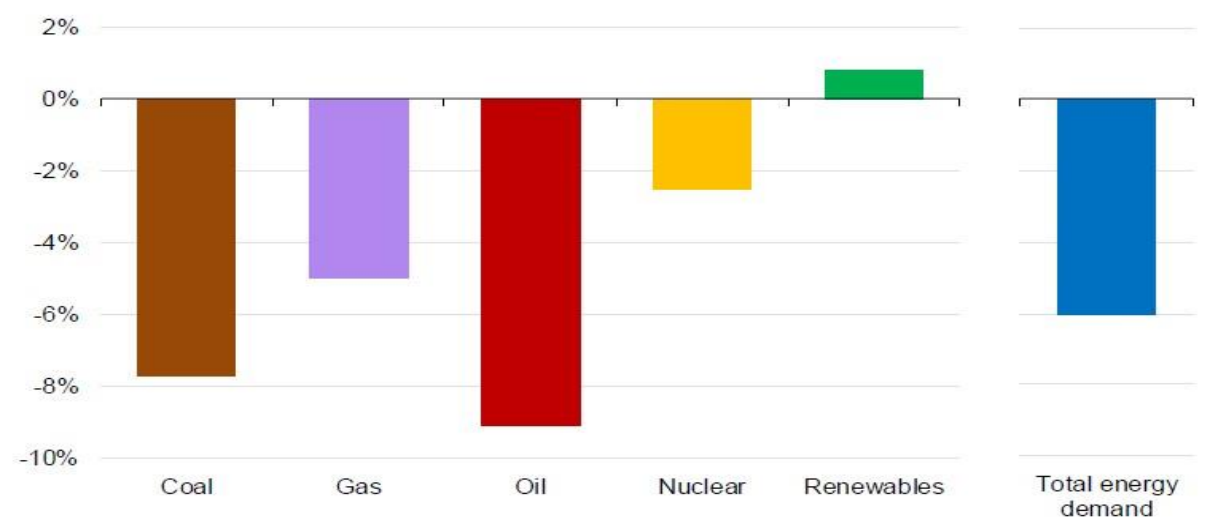

Figura 3: Demanda de energia para 2020 em relação a 2019. Fonte: IEA (2020, p.15).

\footnotetext{
${ }^{9}$ Segundo o relatório: A queda projetada de $6 \%$ seria mais de sete vezes o impacto da crise financeira de 2008 sobre a demanda global de energia. O declínio absoluto da demanda global de energia em 2020 não tem precedentes (IEA,2020, p.15).
} 
Ainda com base nos dados apresentados, podemos inferir que a redução da poluição no mundo, no atual contexto da pandemia, tem reduzido a taxa de mortalidade decorrente da poluição do ar. De acordo com a Organização Mundial da Saúde (OMS), ocorrem anualmente em média 4,2 milhões de mortes prematuras atribuídas à poluição do ar ambiente no mundo (WORLD HEALTH STATISTICS, 2018).

No que se refere à produção e à distribuição de alimentos, a pandemia do coronavírus revelou a vulnerabilidade e as profundas falhas do sistema agroalimentar globalizado. Os efeitos suscitam preocupações com a escassez generalizada de alimentos e aumento de preços, haja vista que, em muitos casos, os alimentos são cultivados em um país ou região, enviados a outro para processamento e, em seguida, reenviados para comercialização em um terceiro país ou região (ALTIERI; NICHOLLS, 2020; GLIESMANN, 2020; HENDRICKSON, 2020).

Deste modo, com a pandemia, torna-se mais urgente a necessidade de transição para sistemas agroalimentares localizados, socialmente justos e ecologicamente resilientes. Gemmill-Herren (2020) observa que já há um aumento sem precedentes na demanda por alimentos locais em muitos países da Europa e da América do Norte. Massy (2020) relata que, na Austrália, desde que a pandemia foi decretada, houve expressivo aumento nas vendas de galinhas poedeiras, sementes vegetais, cursos de cultivo, congeladores e utensílios de jardinagem. O autor também prevê um aumento considerável no número de práticas locais e coletivas de agricultura regenerativa.

\section{A urgência do decrescimento}

A partir da década de 1960, tornou-se cada vez mais evidente a impossibilidade - do ponto de vista ecológico - de expansão do modelo de desenvolvimento capitalista. Desde então, ocorreram diversos encontros, conferências e tratados mundiais para discutir a crise ambiental, gerada pelo padrão de desenvolvimento capitalista. No entanto, pouco tem sido feito para reverter esse quadro e impor limites ao crescimento; pelo contrário, observa-se a intensificação dos ritmos de exploração da natureza e o surgimento de novas manifestações da crise e riscos ecológicos (LOWY, 2013; PORTOGONÇALVES, 2004; SACHS et al., 2002). O fato é que líderes mundiais e instituições políticas, como a ONU e Banco Mundial, continuam a sustentar o crescimento econômico como único horizonte.

A institucionalização da questão ambiental ${ }^{10}$ induziu à criação de um conceito que transmite uma falsa noção de conciliação entre a lógica capitalista e a preservação do meio ambiente, denominado de desenvolvimento

${ }^{10}$ A Conferência Mundial para debater o meio ambiente, realizada em Estocolmo em 1971, representa um marco político dessa institucionalização.

Revbea, São Paulo, V. 15, № 4: 380-401, 2020. 
sustentável11. Profundamente ambíguo e contraditório (VEIGA 2010; LÉNA, 2012; SACHS et al., 2002; DALY, 2004), este conceito foi concebido para facilitar o diálogo entre interesses extremamente divergentes, e como uma aposta na continuidade das relações de produção capitalista. Para BessonGirard (2012, p. 373), o desenvolvimento sustentável é um "oximoro sedativo e mentira consensual".

De acordo com Veiga (2006, p.16):

O conteúdo implícito ou explícito do desenvolvimento é o crescimento econômico, a acumulação de capital, com todos os seus conhecidos efeitos positivos e negativos. E esse núcleo duro está indissoluvelmente ligado às relações sociais bem particulares que são aquelas do modo de produção capitalista.

Em voga atualmente, o desenvolvimento sustentável tornou-se um conceito em disputa, o qual vem sendo apropriado para perpetuação capitalista com uma nova roupagem - "capitalismo verde" (ACOSTA, 2016; LÉNA, 2012; VEIGA, 2010; PORTO-GONÇALVES, 2004; SACHS et al., 2002). Para Daly (2004) e Foster (2015), o termo desenvolvimento sustentável só faz sentido se for entendido como desenvolvimento sem crescimento, aquilo que ele denomina de "estado estacionário". O decrescimento é considerado, portanto, como um processo inevitável para que o desenvolvimento seja realmente sustentável.

Precisamos pensar, portanto, em alternativas radicais, alternativas que coloquem outro horizonte histórico, mais além do capitalismo, mais além das regras de acumulação capitalista e da lógica do lucro e da mercadoria. (LOWY, 2013, p. 81).

O pós-desenvolvimento - corrente teórica na qual se insere o debate sobre o decrescimento e o Bem Viver - se distingue de outros pontos de vista críticos, e alerta para o fato de que todos os esforços de mudança dentro do paradigma dominante visam, antes de qualquer coisa, perpetuar o mesmo sistema (RADOMSKY, 2011; LATOUCHE, 2010; SACHS, 2010), de modo que as "novas roupagens do desenvolvimento - humano e sustentável - não passariam de manobras fraudulentas" (VEIGA, 2006, p. 16). Latouche (2012a) acrescenta que, para os pós-desenvolvimentistas, não se trata de substituir um mau desenvolvimento por um bom, pintando-o de verde ou com as cores do social ou do justo. Por isso, "o decrescimento questiona as crenças que

\footnotetext{
${ }^{11}$ A expressão "desenvolvimento sustentável" foi lançada oficialmente na Conferência das Nações Unidas sobre Meio Ambiente e Desenvolvimento, realizada no Rio de Janeiro em 1992.
} 
levaram a humanidade até o impasse planetário atual" (BESSON-GIRARD, 2012, p. 378).

O termo decrescimento foi utilizado pela primeira vez pelo economista romeno Nicholas Georgescu-Roegen (The Entropy Law and the Economic Process, 1971), considerado atualmente um dos fundadores da teoria da bioeconomia. Na época o conceito não recebeu atenção, pois questionava os postulados da economia clássica, e até então a natureza era vista como uma fonte inesgotável de recursos e criadora de valor econômico.

O conceito ganhou notoriedade somente neste século, tendo como principal referência o economista e filósofo francês Serge Latouche, que foi profundamente influenciado pelas ideias de outros admiráveis filósofos como Ivan Illich (1926-2002) e André Gorz (1923-2007). De origem acadêmica, o decrescimento logo se transformou em um movimento político, necessariamente anticapitalista e que, portanto, não faz parte do discurso de desenvolvimento sustentável, inclusive por conta do seu nome ser propositalmente desagradável o suficiente para que a ordem dominante não se aproprie, como aconteceu com o desenvolvimento sustentável. O ponto de partida é a mudança dos valores que fundamentam nosso estilo de vida e o modo de funcionamento da sociedade.

É preciso introduzir um pouco de altruísmo na sociedade, um pouco mais de cooperação, e modificar totalmente nossas relações com a natureza; devemos nos comportar como bons jardineiros, ao invés de agir como predadores. (LATOUCHE, 2012a, p.49).

O decrescimento não é simplesmente o contrário de crescimento, tampouco significa crescimento negativo; não é um fim em si, porém envolve negar o crescimento ilimitado como meta universal, que negligencia tanto a importância dos vínculos sociais quantos os limites ecológicos. Para isso, Latouche (2012b, p. 4) propõe "descolonizar o imaginário economicista" para redescobrir outros sentidos da vida.

A palavra de ordem decrescimento tem como principal meta enfatizar fortemente o abandono do objetivo do crescimento ilimitado, cujo motor não é outro senão a busca do lucro pelos detentores do capital, com consequências desastrosas para o meio ambiente e, portanto, para a humanidade. Sua meta é uma sociedade em que se viverá melhor trabalhando e consumindo menos (BOCCATO-FRANCO, 2012, p. 269). 
Para Rist (2012), tanto no Norte como no Sul global, o decrescimento se impõe como uma necessidade, e representa uma proposta concreta para uma mudança civilizacional, em resposta à crise social, política, econômica e ecológica. A sua prática envolve uma profunda mudança de valores, que implica em outra economia e renovadas relações sociais. Busca romper a lógica do mercado $e$ as subjetividades consumistas, fomentando as necessidades coletivas e os vínculos sociais. Citando Besson-Girard (2012, p. 379): "O decrescimento nos convida à mais simples e difícil pergunta de todas: o que desejamos que tenha verdadeiramente um sentido em nossa vida?'

Serge Latouche (2010), ao propor este novo modelo de sociedade, baseada no decrescimento, pressupõe que:

A sociedade do decrescimento, em todo caso, o que ela poderá construir a partir da situação atual (mas também, em caso de calamidade, a partir das ruínas ou dos escombros da sociedade do consumo) não abolirá necessariamente o dinheiro, nem os mercados, nem mesmo o salário. Mas, ao mesmo tempo, ela não será mais uma sociedade dominada pelo dinheiro, uma sociedade do todo-mercado, uma sociedade assalariada [...] ela será cada vez menos capitalista, pois terá conseguido abolir o espírito do capitalismo e, em particular, a obsessão do crescimento. (LATOUCHE, 2010, p. 225).

Nesse sentido, Latouche (2009) define o decrescimento como uma utopia concreta e busca especificar os meios de sua realização. Segundo o autor, atualmente, existem iniciativas locais de decrescimento, implementadas em várias partes do mundo, a exemplo dos povos do Equador e da Bolívia que inseriram em sua nova constituição o Sumak Kawsay, termo que, em quéchua, significa Buen Vivir (Latouche, 2012b).

Boccato-Franco (2012), cita os movimentos sociais que questionam explicitamente o capitalismo e possuem pautas convergentes com a proposta do decrescimento, apontando espaços para uma aproximação como, por exemplo, o Movimento dos Atingidos por Barragens (MAB), que questiona a mercantilização da energia, trazendo a proposta de controle popular de um bem comum; o Movimento dos Trabalhadores Rurais Sem Terra (MST) com a sua proposta de reforma agrária popular e agroecológica; o Movimento dos Pequenos Agricultores (MPA) e as demais organizações que compõem a Via Campesina, seguindo a mesma linha.

Entre as principais medidas propostas pelo decrescimento, destacamos: relocalização da economia; redução quantitativa e transformação qualitativa do trabalho, aumento do tempo livre; estabelecimento de uma renda máxima; reforma fiscal; renda universal de existência; acesso universal à saúde; incentivo à agricultura camponesa agroecológica; incentivo à mobilidade ativa 
e/ou transportes coletivos; eliminação da obsolescência programada; reorientação da pesquisa técnico-científica; reconversão tecnológica; mecanismos de combate à especulação fundiária; controle democrático sobre a publicidade e o crédito; rompimento da dependência; respeito aos direitos humanos e às diferenças culturais; e criação de indicadores de desempenho baseados na redução da pegada ecológica e das desigualdades (LÉNA, 2012; LATOUCHE, 2012a; 2009).

Para Rist (2012, p.146), o decrescimento deve contestar o fundamento a teoria econômica dominante - do sistema capitalista, "para não correr o risco de não fazer mais do que arranhar seus contornos, promovendo uma versão revisada e corrigida que só agravará a situação na qual estamos". A sociedade do decrescimento requererá "uma profunda revisão das condições ecológicas, sociais e culturais de produção da riqueza" (BONAIUTI, 2012, p.103).

Indo um pouco mais adiante, no âmbito filosófico, o decrescimento prega a necessidade de reconceituar, ou seja, "repensar os conceitos com os quais abordamos nosso mundo e nossa realidade [...] questionando os conceitos, mudaremos as formas como se produz e as relações de produção" (LATOUCHE, 2012a, p. 49). Para ilustrar, temos como exemplo os conceitos de riqueza e pobreza:

A verdadeira riqueza é feita de bens relacionais, precisamente daqueles que se baseiam na reciprocidade e na não rivalidade, no saber, no amor, na amizade. Inversamente, a miséria é antes de tudo psíquica e resulta do abandono dentro da "multidão solitária", pela qual a modernidade substituiu a comunidade solidária. (LATOUCHE, 2012b, p.15).

Outro exemplo se refere à noção de utilidade, que, de acordo com Rist (2012), foi completamente invertida pela teoria econômica neoclássica, a qual desvinculou o adjetivo útil de sua conotação moral. Hoje, um bem qualquer pode ser qualificado como útil desde que uma pessoa esteja disposta a pagar por ele, visto assim, "tudo o que passa pelo mercado pode ser declarado útil" (RIST, 2012, p. 142). É preciso, portanto, reconceituar a noção de utilidade.

\section{O horizonte do Bem Viver}

O conceito de Bem Viver (Buen Vivir) nasce a partir da visão de mundo dos povos tradicionais, especialmente os ameríndios, que contemplam alguns aspectos em comum como, por exemplo, profunda integração com a natureza (MAMANI, 2010). Esses povos, historicamente marginalizados pelo processo de desenvolvimento capitalista, resistem e empreendem a experiência de reproduzir a vida fora da racionalidade moderna/colonial, manifestando um posicionamento crítico e pluralista, através de "outro modo de existência social" 
(QUIJANO, 2013, p.46). O Bem Viver não é um simples conceito, é uma vivência. (ACOSTA, 2016).

O Bem Viver corresponde às noções de "Sumak Kawsay" na língua Quéchua, "Suma Qamaña" em Aymara e "Nhandereko" em Guarani (ACOSTA, 2016). Ao contrário do decrescimento, que nasce na academia e depois se torna um movimento político, o Bem Viver emerge dos movimentos populares e posteriormente adentra os espaços acadêmicos, passando a englobar perspectivas dos movimentos feministas, ecológicos e decoloniais (ACOSTA, 2016; QUIJANO, 2013; GUDYNAS, 2011; MAMANI, 2010).

O economista equatoriano Alberto Acosta, um dos principais divulgadores da ideia de Bem Viver, autor do livro "O Bem Viver: uma oportunidade para imaginar outros mundos", traz a seguinte definição:

O Bem Viver é uma filosofia de vida que abre as portas para a construção de um projeto emancipador. Um projeto que, ao haver somado histórias de lutas, de resistência e de propostas de mudanças, e ao nutrir-se de experiências locais, posicionase como ponto de partida para estabelecer democraticamente sociedades sustentáveis. (ACOSTA, 2016, p. 40).

O Bem Viver propõe (re)construir relações de harmonia com a natureza - reconhecendo-a como sujeito de direitos - e entre os seres humanos, a partir dos princípios de solidariedade, relacionalidade, reciprocidade, interdependência e complementariedade (ACOSTA, 2016; GUDYNAS, 2011; ESTERMANN, 2012; MAMANI, 2010). Logo, "o Bem Viver não pode ser pensado sem a comunidade" (MAMANI, 2010, p. 32). O Bem Viver representa, portanto, um modo distinto de compreensão (epistemologia) e intervenção (ontologia) do/no mundo.

Nas últimas décadas, o Bem Viver passou a ser pauta de reivindicação dos movimentos sociais indígenas na América Latina, ao questionarem o modelo desenvolvimentista oriundo de um padrão de modernidade eurocêntrico colonial, antropocêntrico e patriarcal. Dessa forma, o Bem Viver é construído a partir de posições que exigem um novo tipo de relação dos seres humanos entre si e com a natureza (ACOSTA, 2016; ESTERMANN, 2012; QUIJANO, 2013; GUDYNAS, 2011).

De fato, "sem romantizá-las, as comunidades indígenas - portadoras de uma longa memória - têm demonstrado que os seres humanos podem organizar modos de vida sustentáveis" (ACOSTA, 2020, p. 4, tradução nossa). Isso não significa uma pregação de retorno ao passado, já que se trata da crítica de um sistema de valores e não necessariamente das técnicas em si. " $O$ Bem Viver não tem uma postura anti-tecnológica” (GUDYNAS, 2011, p.14). 
O Bem Viver representa um projeto político de construção de alternativas ao desenvolvimento (DOURADO, 2020; GUDYNAS, 2011). Em debate por diversos segmentos da esquerda mundial no século 21, ganhou visibilidade e importância ao assumir a centralidade nas novas constituições ${ }^{12}$ do Equador (2008) e da Bolívia (2009) como objetivo social a ser perseguido pelo Estado e por toda a sociedade.

Para se concretizar em nível global, o Bem Viver exige outra economia, "que se reencontre com a natureza e atenda às demandas da sociedade, não às do capital' (ACOSTA, 2016, p. 99), e isso implica em novos padrões de produção, de sociabilidade, de consumo e de distribuição (QUIJANO, 2013; ESTERMANN, 2012). Acreditamos que "a proposta do Bem Viver, desde que assumida efetivamente pela sociedade, pode projetar-se com força nos debates mundiais" (ACOSTA, 2016, p.38).

\section{Considerações finais}

Não sabemos como será o mundo pós-pandemia. Devemos encarar as incertezas e, ao mesmo tempo, tirar lições deste momento, tendo em vista que a pandemia expôs as profundas contradições do capitalismo. "Pensar-se-á que esta normalidade foi a que conduziu à pandemia e conduzirá a outras no futuro?" (SANTOS, 2020, p. 30). Se o mundo pós-pandemia voltar a ser como era antes, provavelmente será numa versão piorada. Deste modo, estamos diante de uma encruzilhada: ou permaneceremos reféns da normalidade capitalista ou caminharemos rumo a um novo horizonte de sentido histórico, rompendo com os velhos paradigmas e abrindo espaço para novos a partir de novos lugares de enunciação.

Estes novos paradigmas emergem a partir das lutas sociais e dos ensaios contra-hegemônicos que seguem acontecendo dentro e a partir das possibilidades reais dadas, por isso, síntese das contradições. Citando Milton Santos (2013, p. 45): "cada época se caracteriza pelo aparecimento de um conjunto de novas possibilidades concretas". O Bem Viver e o decrescimento, conjugados, fornecem novas possibilidades concretas de mudança de paradigma e reinvenção do modo de vida, em resposta à atual crise (caos sistêmico) do capitalismo.

\section{Referências}

ACOSTA, A. 0 bem viver: uma oportunidade para imaginar outros mundos. Tradução de Tadeu Breda. São Paulo: Autonomia Literária, 2016. 257 p.

12 A inclusão do Bem Viver no marco legal até hoje não alterou os padrões de produção capitalista, porém tem gerado novos discursos e práticas que pautam possibilidades e prefiguram caminhos para uma transição. 
ACOSTA, A. Reecuentro con la Madre Tierra: Tarea urgente para enfrentar las pandemias. Revista Nueva América, n.166, 2020.

ALTIERI, M; NICHOLLS, C. Agroecology and the emergence of a post COVID-19 agriculture. Agriculture and Human Values, 2020. DOI: https://doi.org/10.1007/s10460-020-10043-7

ARRIGHI, G. Caos e governabilidade no sistema mundial moderno. São Paulo, Contraponto, 2001.

BESSON-GIRARD, J. Por uma conversão antropológica: o decrescimento é a saída do labirinto. In: LÉNA, P; NASCIMENTO, E. P. (Org.). Enfrentando os limites do crescimento: Sustentabilidade, decrescimento e prosperidade. Rio de Janeiro: Garamond, 2012.p. 371-380.

BOCCATO-FRANCO, A. O decrescimento no Brasil. In: LÉNA, P; NASCIMENTO, E. P. (Org.). Enfrentando os limites do crescimento: Sustentabilidade, decrescimento e prosperidade. Rio de Janeiro: Garamond, 2012. p. 269-288.

BONAIUTI, M. A caminho da grande transição. In: LÉNA, P; NASCIMENTO, E. P. (Org.). Enfrentando os limites do crescimento: Sustentabilidade, decrescimento e prosperidade. Rio de Janeiro: Garamond, 2012. p.79-106.

CASTELLS, M. A hora do grande reset. Outras Palavras, São Paulo, 27 de abril de 2020. Disponivel em: <https://outraspalavras.net/poscapitalismo/castells-a-hora-do-grande-reset/> Acesso em: 20 de maio 2020.

DALY, E. H. Crescimento sustentável? Não, obrigado. Ambiente \& Sociedade, v. 7, n.2, 2004. Disponível em:< https://www.scielo.br/pdf/asoc/v7n2/24695.pdf>

DAVIS, M. A crise do coronavírus é um monstro alimentado pelo capitalismo. In: DAVIS, M., et al. (Orgs.). Coronavírus e a luta de classes. Brasil: Terra sem Amos, 2020. p.05-12.

DOURADO, N.P. O paradigma do Bem Viver: do desenvolvimento alternativo à alternativas ao desenvolvimento. Revista Contraponto, v.7, n.1, 2020. Disponível em: <https://seer.ufrgs.br/contraponto/article/view/100721> Acesso em: 26 maio de 2020.

ESTERMANN, J. Crisis civilizatoria y Vivir Bien: Una crítica filosófica del modelo capitalista desde el allin kawsay/suma qamaña andino. Polis: Revista de la Universidad Bolivariana, La Paz, v. 33, n. 11, p.149-174, 2012.

FOSTER, J.B. Uma catástrofe no século XXI, a menos que a humanidade mude subitamente de rumo. IHU, São Leopoldo, 08 de abril de 2020. Disponível em: <http://www.ihu.unisinos.br/78-noticias/597888-uma-catastrofeno-seculo-xxi-a-menos-que-a-humanidade-mude-subitamente-de-rumoentrevista-com-john-bellamy-foster> Acesso em: 20 de maio de 2020. 
FOSTER, J.B. Marxismo e Ecologia: fontes comuns de uma Grande Transição. Lutas Sociais, São Paulo, v. 19, n. 35, p.80-97, jul. 2015. Disponível em: <https://revistas.pucsp.br/ls/article/view/26680> Acesso em: 12 jun. de 2020.

GEMMILL-HERREN, B. Closing the circle: an agroecological response to COVID-19. Agriculture and Human Values, 2020. DOI: https://doi.org/10.1007/s10460-020-10097-7

GEORGESCU-ROEGEN, N. The entropy law and economic process. Cambridge: Harvard University Press, 1971.

GIATTI, L. A reflexão da COVID-19: evoluindo do individualismo para a colaboração mútua. Diálogos Socioambientais: Dossiê Covid-19, São Paulo, v. 3, n. 6, p. 35-37, maio 2020. Trimestral.

GLIESMANN, S.R.Transforming food and agriculture systems with agroecology. Agriculture and Human Values, 2020. DOI: https://doi.org/10.1007/s10460$\underline{\text { 020-10058-0 }}$

GUDYNAS, E. Buen Vivir: germinando alternativas al desarollo. América Latina em Movimiento, ALAI, n.462: 1- 20. Quito, 2011.

HARVEY, D. 17 contradições e o fim do capitalismo. São Paulo: Boitempo, 2016.

HARVEY, D. Política anticapitalista em tempos de COVID-19. In: DAVIS, Mike, et.al (Orgs.). Coronavírus e a luta de classes. Brasil: Terra sem Amos, 2020. p.13-24.

HENDRICKSON, M.K. Covid lays bare the brittleness of a concentrated and consolidated food system. Agriculture and Human Values, 2020. DOI: https://doi.org/10.1007/s10460-020-10092-y

IEA. Global Energy Review 2020, Internacional Energy Agency, Paris, 2020. Disponível em: <https://www.iea.org/reports/global-energy-review2020> Acesso em: 12 maio de 2020.

KRENAK, A. O amanhã não está à venda. São Paulo: Companhia das Letras, 2020.

LATOUCHE, S. Pequeno Tratado do Decrescimento Sereno. Tradução: Claudia Berliner. São Paulo: WMF Martins Fontes, 2009.

LATOUCHE, S. Existira uma vida após o desenvolvimento? Estudos de Sociologia, v. 16, n. 2, p. $217-230,2010$. 
LATOUCHE, S. O decrescimento. Por que e como? In: LÉNA, P.; NASCIMENTO, E.P. (Org.). Enfrentando os limites do crescimento: Sustentabilidade, decrescimento e prosperidade. Rio de Janeiro: Garamond, 2012a. p.45 - 53.

LATOUCHE, S. Convivialidade e Decrescimento. Cadernos IHU ideias, São Leopoldo, Universidade do Vale do Rio dos Sinos (UNISINOS), ano 10, n. 166, 2012b.

LEFF, E. Racionalidade Ambiental: a reapropriação social da natureza. Rio de Janeiro: Civilização Brasileira. 2006

LÉNA, P. Os limites do crescimento econômico e a busca pela sustentabilidade: uma introdução ao debate. In: LÉNA, P; NASCIMENTO, E. P. (Org.). Enfrentando os limites do crescimento: Sustentabilidade, decrescimento e prosperidade. Rio de Janeiro: Garamond, 2012. p. 45-55.

LÖWY, M. Crise ecologica, crise capitalista, crise de civilização: a alternativa ecossocialista. Caderno CRH, Salvador, v. 26, n.67, p. 79 - 86, 2013.

MAMANI, F. H. Buen Vivir / Vivir Bien: filosofia, politicas, estratégias experiências regionales andinas. Lima, Peru, 2010.

MANDEL, E. Le capitalisme. Enciclopédia Universalis, 1981.

MARQUES, L. Capitalismo e colapso ambiental. $3^{\text {a }}$ ed. rev.ampl. - Campinas: Editora da Unicamp, 2018.

MARQUES, L. A pandemia incide no ano mais importante da história da humanidade. Serão as próximas zoonoses gestadas no Brasil? Seção: CIÊNCIA, SAÚDE E SOCIEDADE: COVID-19, UNICAMP, Campinas, 05 de maio de 2020.2 Disponível em: $<$ https://www.unicamp.br/unicamp/noticias/2020/05/05/pandemia-incide-no-anomais-importante-da-historia-da-humanidade-serao-proximas $>$. Acesso em: 12 maio 2020.

MARX, K. O capital: crítica da economia política, livro I. São Paulo: Abril Cultural, 1984.

MASSY, C. COVID-19, the Anthropocene, and transformative change. Agriculture and Human Values, 2020. DOI: https://doi.org/10.1007/s10460020-10080-2

MÉSZÁROS, I. Para além do capital: rumo a uma teoria da transição. São Paulo: Boitempo, 2011.

MÉSZÁROS, I. O desafio e o fardo do tempo histórico: o socialismo no séc. XXI. São Paulo: Boitempo, 2007. 
NETO, J.A.S.; CASTRO, F.M. Capitalism über alles: uma interpretação da pandemia de coronavírus no Brasil à luz da geografia radical de Neil Smith. Espaço e Economia, n.18, $2020 . \quad$ DOI: https://doi.org/10.4000/espacoeconomia.12104

PORTO-GONÇALVES, C.W. O desafio ambiental. Rio de Janeiro: Record, 2004.

PORTO-GONÇALVES, C.W. De neoliberais e de keynesianos em tempos de Coronavírus. Espaço e Economia, n.18, 2020. DOI: https://doi.org/10.4000/espacoeconomia.11699

QUIJANO, A. Bem Viver": entre o "desenvolvimento" e a "des/colonialidade"do poder. Rev. Fac. Dir. UFG, v. 37, n. 1, p. 46-57, 2013.

RADOMSKY, G. F. Desenvolvimento, Pós-estruturalismo e Pósdesenvolvimento: a crítica da modernidade e a emergência de "modernidades alternativas". Revista Brasileira de Ciências Sociais, São Paulo, v.26, n.75, p. 149-162, 2011.

RIST, G. O decrescimento para todos? In: LÉNA, P; NASCIMENTO, E. P. (Org.). Enfrentando os limites do crescimento: Sustentabilidade, decrescimento e prosperidade. Rio de Janeiro: Garamond, 2012. p.135 -156.

SACHS, W. et al. Justiça num mundo frágil: Memorando para a cúpula mundial sobre desenvolvimento sustentável. Tradução: Renato Aguiar. Rio de Janeiro: Fundação Heinrich Böll, 2002.

SANTOS, B. S. A cruel pedagogia do vírus. Coimbra: Almedina, 2020.

SANTOS, M. Técnica, Espaço, Tempo: Globalização e Meio Técnicocientifico-informacional. $5^{\underline{a}}$ ed., 1. reimpr. São Paulo: Editora da Universidade de São Paulo, 2013.

SATO, M.; SANTOS, D; SÁNCHEZ, C. Vírus: simulacro da vida? Rio de Janeiro: GEA-SUR, UNIRIO, 2020.

THE EDITORIAL BOARD. Virus lays bare the frailty of the social contract: radical reforms are required to forge a society that will work for all. Financial Times. Londres, $\quad 3 \quad$ abr. $2020 . \quad$ Disponível em: $<$ https://www.ft.com/content/7eff769a-74dd-11ea-95fe-fcd274e920ca $>$. Acesso em: 10 maio de 2020.

VEIGA, J E. Neodesenvolvimentismo: quinze anos de gestação. São Paulo em Perspectiva, São Paulo, v. 20, n. 3, p.1-25, set. 2006.

VEIGA, J E. Desenvolvimento sustentável: o desafio do século XXI. Rio de Janeiro: Garamound, 2010. 
WALLACE, R. G. Big Farms Make Big Flu: Dispatches on Infectious Disease, Agribusiness, and the Nature of Science. New York: Monthly Review Press, 2016.

WALLERSTEIN, I. Structural crises. New Left Review, n. 62, p. 133-142, 2010.

WORLD HEALTH ORGANIZATION. WORLD HEALTH STATISTICS 2018: monitoring health for the SDGs, sustainable development goals. Geneva: World Health Organization; 2018. Disponível em: $<$ https://apps.who.int/iris/bitstream/handle/10665/272596/9789241565585eng.pdf?ua $=1 \& u a=1>$. Acesso em: 06 maio 2020.

ZIZEK, S. Um golpe como "Kill Bill" no capitalismo. In: DAVIS, M. et al. (Orgs.). Coronavírus e a luta de classes. Brasil: Terra sem Amos, 2020. p.05-12. 